\title{
STABILITY OF A PEXIDER TYPE FUNCTIONAL EQUATION RELATED TO DISTANCE MEASURES
}

\author{
Gwang Hui Kim And Prasanna K. SAHOO
}

Abstract. This work aims to study of the stability of two generalizations of the functional equation $f(p r, q s)+f(p s, q r)=f(p, q) f(r, s)$, namely (i) $f(p r, q s)+g(p s, q r)=h(p, q) h(r, s)$, and (ii) $f(p r, q s)+g(p s, q r)=h(p, q) k(r, s)$ for all $p, q, r, s \in G$, where $G$ is a commutative semigroup. Thus this work is a continuation of our earlier works [15] and [16], and the functional equations studied here arise in the characterizations of symmetrically compositive sum form distance measures.

Mathematics subject classification (2010): 39B82, 39B52.

Keywords and phrases: Stability, superstability, functional equation, multiplicative function.

\section{REFERENCES}

[1] J. BRZDEK, A. NAJDECKI, B. XU, Two general theorems on superstability of functional equations, Aequationes Math., Doi: 10.1007/s00010-014-0266-6.

[2] J. BRZDeK, K. CiePlinski, Hyperstability and superstability, Abstract and Applied Analysis 2013 (2013), Article ID 401756, 13 pages.

[3] J. K. Chung, Pl. Kannappan, C. T. Ng And P. K. Sahoo, Measures of distance between probability distributions, J. Math. Anal. Appl., 138 (1989), 280-292.

[4] D. H. Hyers, G. Is AC AND TH. M. RASSiAs, Stability of Functional Equations in Several Variables, Birkhäuser, Boston, 1998.

[5] Pl. Kannappan And G. H. Kim, On the stability of the generalized cosine functional equations, Ann. Acad. Pedagog. Crac. Stud. Math., 1 (2001), 49-58.

[6] Pl. Kannappan and P. K. Sahoo, Sum form distance measures between probability distributions and functional equations, Int. J. Math. Stat. Sci., 6 (1997), 91-105.

[7] Pl. Kannappan, P. K. Sahoo And J. K. Chung, An equation associated with the distance between probability distributions, Ann. Math. Silesianae, 8 (1994), 39-58.

[8] Pl. Kannappan, P. K. Sahoo and J. K. Chung, On a functional equation associated with the symmetric divergence measures, Utilitas Math., 44 (1993), 75-83.

[9] G. H. Kim, On the Stability of the Pexiderized trigonometric functional equation, Appl. Math. Compu., 203 (2008), 99-105.

[10] G. H. KIM, On the stability of Mixed Trigonometric Functional Equations, Banach J. Math. Anal., 1, No. 2 (2007), 227-236.

[11] G. H. KIM, The stability of the d'Alembert and Jensen type functional equations, Jour. Math. Anal. Appl., 325 (2007), 237-248.

[12] G. H. KIM, A stability of the generalized sine functional equations, Jour. Math. Anal. Appl., 331 (2007), 886-894.

[13] G. H. Kim And Y. W. LeE, The superstability of the Pexider type trigonometric functional equation, Aust. J. Math. Anal., submitted.

[14] G. H. Kim And Y. W. LeE, Boundedness of approximate trigonometric functions, Appl. Math. Lett., 22 (2009), 439-443.

[15] G. H. Kim AND P. K. SAHoo, Stability of a functional equation related to distance measures - I, Appl. Math. Lett., 24 (2011), 843-849. 
[16] G. H. Kim AND P. K. SAhoo, Stability of a functional equation related to distance measures - II, Ann. Funct. Anal., 1 (2010), 26-35.

[17] A. NAJDECKI, The stability of a functional equation connected with the Reynold operator, J. Inequal. Appl., (2007), 1-3.

[18] T. RIEDEL AND P. K. SAHOO, On a generalization of a functional equation associated with the distance between the probability distributions, Publ. Math. Debrecen, 46 (1995), 125-135.

[19] T. Riedel AND P. K. SAHoo, On two functional equations connected with the characterizations of the distance measures, Aequationes Math., 54 (1998), 242-263.

[20] P. K. SAHOO, On a functional equation associated with stochastic distance measures, Bull. Korean Math. Soc., 36 (1999), 287-303. 